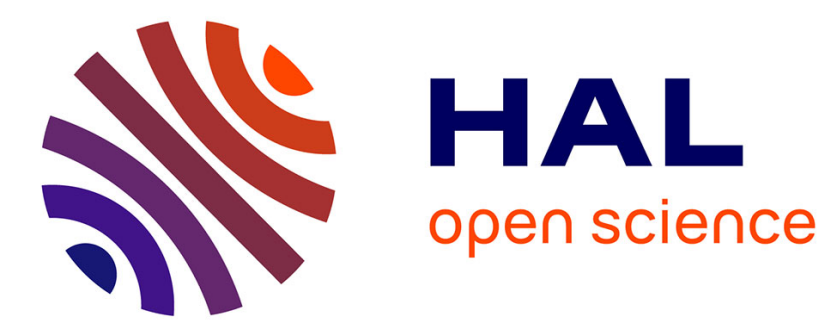

\title{
Attenuation tomography of the upper mantle
}

\author{
Alice Adenis, E. Debayle, Y. Ricard
}

\section{To cite this version:}

Alice Adenis, E. Debayle, Y. Ricard. Attenuation tomography of the upper mantle. Geophysical Research Letters, 2017, 44 (15), pp.7715-7724. hal-02046705

\section{HAL Id: hal-02046705 \\ https://hal.science/hal-02046705}

Submitted on 28 Dec 2021

HAL is a multi-disciplinary open access archive for the deposit and dissemination of scientific research documents, whether they are published or not. The documents may come from teaching and research institutions in France or abroad, or from public or private research centers.
L'archive ouverte pluridisciplinaire HAL, est destinée au dépôt et à la diffusion de documents scientifiques de niveau recherche, publiés ou non, émanant des établissements d'enseignement et de recherche français ou étrangers, des laboratoires publics ou privés. 


\section{Geophysical Research Letters}

\section{RESEARCH LETTER}

10.1002/2017GL073751

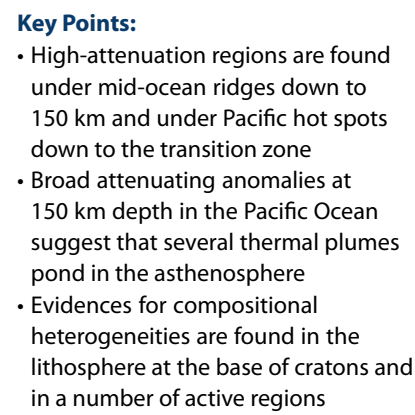

Supporting Information:

- Supporting Information S1

- Supporting Information S2

- Figure S1

- Figure S2

- Figure S3

- Figure S4

- Figure S5

- Figure S6

- Figure S7

- Figure S8

- Figure S9

Correspondence to:

A. Adenis,

Alice.Adenis@ens-lyon.fr

\section{Citation:}

Adenis, A., E. Debayle, and Y. Ricard (2017), Attenuation tomography of the upper mantle, Geophys. Res. Lett., 44, 7715-7724, doi:10.1002/2017GL073751.

\section{Received 11 APR 2017}

Accepted 13 JUL 2017

Accepted article online 18 JUL 2017

Published online 5 AUG 2017
@2017. American Geophysical Union. All Rights Reserved.

\section{Attenuation tomography of the upper mantle}

\author{
Alice Adenis ${ }^{1}$ (D) Eric Debayle $^{1}$ (D), and Yanick Ricard ${ }^{1}$ (D) \\ ${ }^{1}$ Laboratoire de Géologie de Lyon-Terre, Planètes, Environnement, CNRS, UMR 5276, École Normale Supérieure de Lyon, \\ Université de Lyon, Université Claude Bernard Lyon 1, 2 rue Raphaël Dubois, Villeurbanne, France
}

\section{Introduction}

One of the goals of seismology is to map the various physical properties of the Earth such as temperature, composition, volatile content, or presence of partial melt. This goal will only be reached by the cross analysis of multiple observations that have different sensitivities to these quantities. Therefore, mapping anelasticity in addition to elastic velocity or anisotropy is critical. In addition, a better knowledge of anelasticity allows a more accurate estimate of seismic velocities, by taking into account the physical dispersion due to attenuation [Romanowicz, 1990; Karato, 1993].

A number of recent global tomographic studies focus on the elastic structure in the upper mantle [e.g., Ritsema et al., 2004; French et al., 2013; Schaeffer and Lebedev, 2013; Debayle et al., 2016], but progress in mapping the anelastic structure has been much slower (see, e.g., Romanowicz and Mitchell [2007] for a review) because extracting and inverting properly the amplitude of waveforms to obtain an attenuation model is a difficult problem. Uncertainties in the source excitation, in the local site response and in the calibration of the measuring devices, strongly influence the measurement of the amplitude [Um and Dahlen, 1992; Dalton et al., 2014]. Propagation effects, such as the geometrical spreading of the wavefront, the effect of focusing and defocusing [Lay and Kanamori, 1985; Woodhouse and Wong, 1986], and the short wavelength scattering [e.g., Ricard et al., 2014], affect the wave amplitude, and these nondissipative effects must be corrected for in order to access the intrinsic attenuation that carries information about the anelastic structure. Intrinsic attenuation results from mechanisms such as interaction of the waves with crystal dislocations, grain interfaces, phase changes, or partial melting [Jackson, 2007; Faul and Jackson, 2015; Durand et al., 2012].

The pattern of attenuation in global attenuation models is coherent with large-scale surface tectonics down to about 200-250 km depth. They also present a negative correlation with velocity patterns (large $1 / Q$ correlates with low velocities) [see, e.g., Ma et al., 2016; Dalton et al., 2008; Dalton and Ekström, 2006; Billien et al., 2000]. However, despite recent improvements [Dalton et al., 2017], the agreement among attenuation models remains generally low. While in some models the quality factor increases with seafloor age similarly to the velocity [Ma et al., 2016; Dalton et al., 2008; Warren and Shearer, 2002], others suggest that large-scale attenuating anomalies are rather correlated at asthenospheric depths with the hot spot distribution under the Pacific and the southern Indian Ocean [Gung and Romanowicz, 2004; Romanowicz, 1995; Adenis et al., 2017]. Part of these differences may be due to different modeling techniques and to the way focusing-defocusing terms are treated. While some authors reject paths that might be strongly affected by focusing effects [Romanowicz, 1995; Gung and Romanowicz, 2004], others account for focusing using great circle linearized 
ray theory [Billien et al., 2000; Dalton and Ekström, 2006; Dalton et al., 2008; Adenis et al., 2017] or 2-D finite-frequency sensitivity kernels [Ma et al., 2016].

In this study, we present QsADR17, a new 3-D shear wave attenuation model, based on a global data set of attenuation measurements for Rayleigh waves in the period range 40-240 s, for the fundamental and up to the fifth overtone [Debayle and Ricard, 2012]. This data set was obtained from a waveform inversion [Cara and Lévêque, 1987] which accounts for the interference between the different modes present in a surface wave seismogram, allowing a proper extraction of fundamental and higher-mode information. The bulk attenuation is assumed to be zero in these inversions. In a previous paper [Adenis et al., 2017], we introduced QADR17, a set of attenuations maps at different periods built from the fundamental mode of Rayleigh waves. QsADR17 is obtained after completing this data set with higher-mode attenuation maps and inverting for a 3-D model of the shear wave quality factor $Q_{\mu}$.

\section{Regionalization}

The initial data set consists of 372,629 epicenter station path-average attenuation curves measured in the period range 40-240 s for the fundamental mode and up to the fifth overtone. From these observations, fundamental mode attenuation maps were obtained by Adenis et al. [2017]. We supplement these maps with higher-mode attenuation maps based on Debayle and Ricard's [2012] data set. All together 46 attenuation maps at different periods and modes are considered in this study and 15 of them are depicted in Figure 1.

Here we only summarize the main specificities of the regionalization which is described in details in Adenis et al. [2017]:

1. A thorough data selection is applied to reject data likely to be biased by errors in the source or in the instrumental response.

2. We use great circle ray theory and focusing effects are accounted for along each ray using the formalism of Woodhouse and Wong [1986].

3. We discard paths longer than $110^{\circ}$ where Woodhouse and Wong's [1986] formalism overestimates the amplitudes [Dalton et al., 2014].

4. Unlike earlier studies, we invert for $\ln (Q)$ rather than for $Q$ or $Q^{-1}$. This brings the data close to a Gaussian distribution, avoids unphysical negative values, and allows for a much larger range of variations.

5. All maps are obtained using a Gaussian correlation function having a standard deviation of $10^{\circ}$ and an a priori error set to $20 \%$ of the a priori model. This means that our maps include all spherical harmonics degree up to $\approx 16$ and that, within two standard deviations, the inverted $Q$ is likely between $Q_{0}^{0.4}$ and $Q_{0}^{-0.4}$ times the a priori quality factor $Q_{0}\left(Q\right.$ is expected in between $\approx 1200$ and $\approx 32$ for $\left.Q_{0}=200\right)$.

Details are given in section S1 in the supporting information to illustrate these characteristics [Cara and Lévêque, 1987; Debayle and Ricard, 2012].

\section{Inversion at Depth}

We extract at each geographical point of latitude $\theta$ and longitude $\phi$, the ensemble of the $46 \ln \left(Q\left(T_{k}, n, \theta, \phi\right)\right)$ measurements at period $T_{k}$ and for the mode $n$, that are inverted to obtain a 1-D depth-dependent $\ln \left(Q_{\mu}(z, \theta, \phi)\right)$ profile. The juxtaposition of these $Q_{\mu}(z, \theta, \phi)$ profiles at each geographical point leads to a 3-D model of shear attenuation. Again, we keep our parametrization in term of logarithms with all its advantages (positivity, Gaussian variances, and large variations).

At each point $(\theta, \phi)$ the problem to solve is to find the local attenuation in $j$ layers $Q_{\mu_{j}}^{-1}$ when the attenuation $Q_{i}^{-1}$ is known for the observation $i\left(i\right.$, up to 46 , accounts for $n$ modes and $T_{k}$ periods):

$$
Q_{i}^{-1}=\sum_{j} \mathcal{K}_{i j} Q_{\mu_{j}}^{-1}
$$

where $\mathcal{K}_{i j}$ are known attenuation kernels $\left(\mathcal{K}_{i j}=\partial Q_{i}^{-1} / \partial Q_{\mu_{j}}^{-1}\right)$. We introduce logarithms and define the data $d_{i}$ and the parameters $m_{j}$ as $d_{i}=\ln Q_{i}^{-1}$ and $m_{j}=\ln Q_{\mu_{j}}^{-1}$. The direct problem can be expressed as:

$$
d_{i}=\ln \left(Q_{i}^{-1}\right)=\ln \left[\sum_{j} \mathcal{K}_{i j} Q_{\mu_{j}}^{-1}\right]=\ln \left[\sum_{j} \mathcal{K}_{i j} e^{m_{j}}\right]
$$



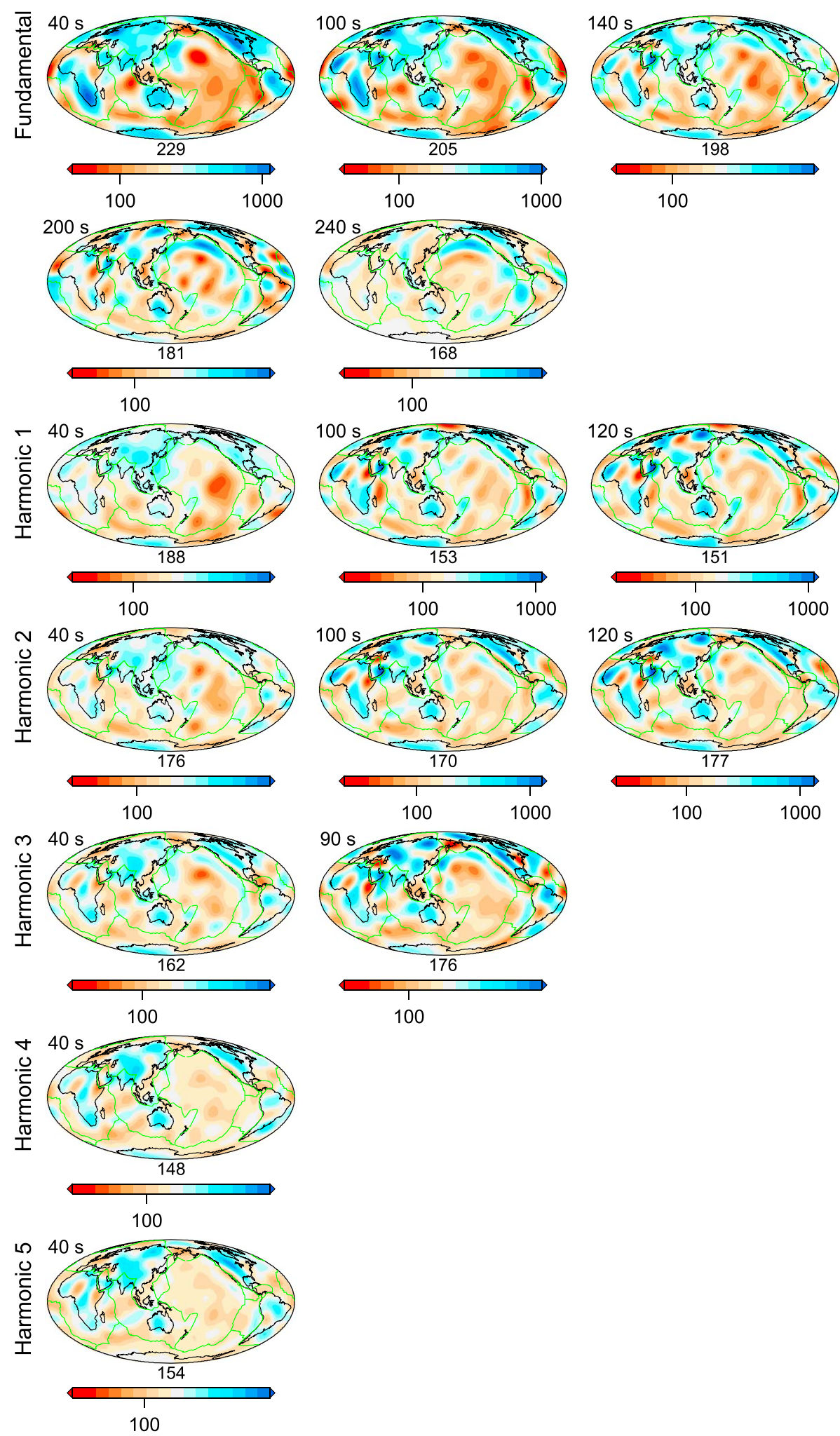

Figure 1. Attenuation maps of Rayleigh waves, at different periods and for different modes. $Q_{T}$ is plotted with a logarithmic scale. Its geometrical average is reported above the color scale. Plate contours are in green. 
This nonlinear problem $d_{i}=g_{i}\left(m_{j}\right)$ can be solved using the iterative least squares solution of Tarantola and Valette [1982] in a way very similar to what has been done during the first step of regionalization [Adenis et al., 2017]. The partial derivatives, $\partial g_{i} / \partial m_{j}$ can be expressed as follows:

$$
\mathbf{G}_{i j}=\frac{\partial \ln Q_{i}}{\partial \ln Q_{\mu_{j}}} .
$$

The inversion proceeds iteratively, where a model $Q_{j}^{(p)}$ at iteration $p$ is used to compute the $\mathcal{K}_{i j}$ and $G_{i j}$, which allows to estimate an improved model $Q_{j}^{(p+1)}$. We performed six iterations in all the inversions presented in this paper. We observed very little evolution of the model after the first iteration and in all cases, our inversions had definitely converged at iteration six.

The data and model a priori information are handled through the definition of covariance matrices. The a priori data covariance matrix is diagonal and contains at each period and for each mode the variance of the corresponding attenuation map. The a priori model covariance matrix is nondiagonal, and a Gaussian correlation function couples the attenuation variations at different depths. This correlation function is defined by a standard deviation $\sigma$ controlling the amplitude of the model perturbation and by a vertical correlation length $L_{\text {corr }}=50 \mathrm{~km}$, controlling the vertical smoothness. The standard deviation $\sigma$ decreases from 1.2 at $50 \mathrm{~km}$ to 0.4 at $650 \mathrm{~km}$ depth, (i.e., within two standard deviations $Q_{\mu}$ can vary laterally by a factor $\exp (2.4) \approx 11$ at $50 \mathrm{~km}$ and $\exp (0.8) \approx 2.2$ at $650 \mathrm{~km}$ ), in agreement with the range of variations observed by Debayle and Ricard [2012]. Notice that by using logarithms both for the regionalization and for the depth-dependent inversion, we allow for very large variations of the quality factor without the risk of getting negative values (see also section $\mathrm{S} 1$ in the supporting information).

At each geographical point, the starting and a priori model of the inversion includes a crust with a constant $Q_{\mu}=600$ and the thickness taken from 3SMAC [Nataf and Ricard, 1995] underlain by the elastic parameters and the density of preliminary reference Earth model (PREM) [Dziewoński and Anderson, 1981]. Debayle and Ricard [2012] noticed that the attenuating layer located between 80 and $220 \mathrm{~km}$ depth in PREM is not adapted to continental paths. We use therefore a uniform 1-D quality factor $Q_{\mu}(z)=200$ as a starting upper mantle model. We assume that the crust properties are those of 3SMAC and only invert for the mantle structure. Sensitivity kernels are calculated at each geographical point using the formalism of Takeuchi and Saito [1972]. We show in section S2 in the supporting information the kernels $\partial \ln \left(Q_{i}\right) / \partial Q_{\mu}^{-1}(z)$ calculated for PREM. The use of Rayleigh wave overtones provides sensitivity in the whole upper mantle.

\section{Results}

Figure 2 depicts QsADR17 at different depths in the upper mantle. Various tests are discussed in section S2 in the supporting information to assess the robustness of this model [Dalton et al., 2008; Durek and Ekström, 1996; Nataf and Ricard, 1995; Dziewoński and Anderson, 1981].

In the uppermost $150 \mathrm{~km}$, QsADR17 shows a strong correlation with surface tectonics, the difference between continents and oceans being the dominant signal. In this depth range, continents are associated with low attenuation, especially beneath old continental roots, such as the African, North American, Amazonian, Siberian and Australian cratons, the Russian platform, and Antarctica. Oceans are more attenuating than continents, and the highest attenuations are found beneath the mid-ocean ridges at 50 and $100 \mathrm{~km}$ depths and also in old oceanic basins generally in the vicinity of hot spots. The correlation with hot spots is particularly clear at $50 \mathrm{~km}$ depth where attenuation anomalies underlain most hot spots in the Pacific (including Hawaii, Samoa, Marquesas, Society, and Galapagos), in the Indian Ocean (e.g., Reunion, Kerguelen, Amsterdam, and Marion), and in the Atlantic (e.g., Meteor, Tristan da Cunha-Gough, and Cap Verde).

If the attenuating signature of mid-ocean ridges vanishes below $150 \mathrm{~km}$ depth, high-attenuation anomalies persist deeper beneath hot spots. This is particularly clear in the Pacific Ocean where the attenuating anomalies associated with Hawaii and the South Pacific hot spots persist down to the base of the upper mantle. The attenuating anomaly is clear in the whole depth range of inversion beneath Hawaii, and its maximum is shifted to the northeast of the surface location of the hot spot. A low-attenuation region beneath the Tibetan plateau extends down to transition zone depths and may be associated with the subduction of India. At $250 \mathrm{~km}$ depth, low attenuations surround the Pacific Ocean and correlate with the location of subduction zones. Finally, a strong attenuation anomaly underlies the eastern part of China from 350 to $610 \mathrm{~km}$ depth. 

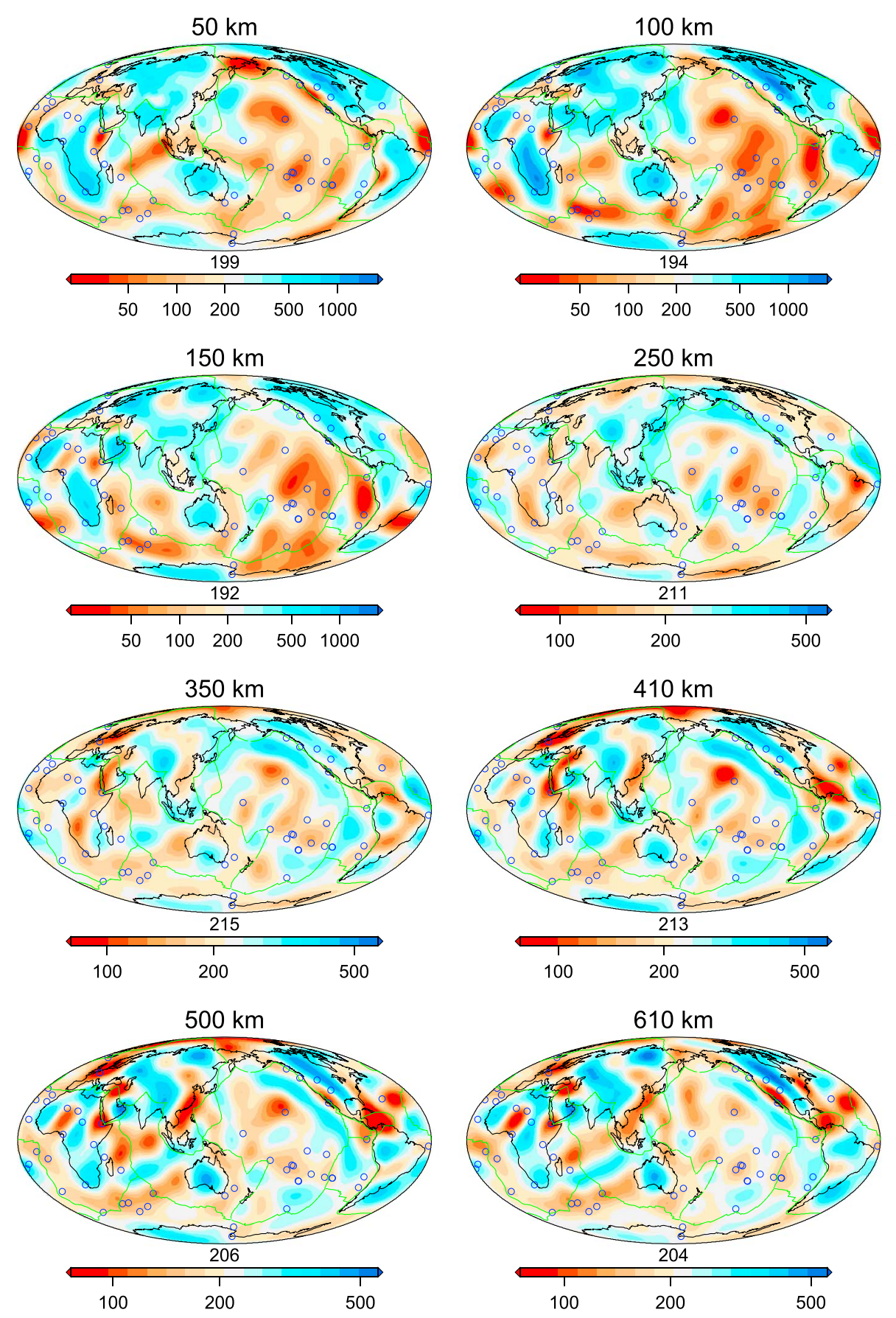

Figure 2. $S$ wave attenuation maps at different depths in the upper mantle. $Q_{\mu}$ is plotted with a logarithmic scale. Its geometrical average is reported above the color scale. Hot spot locations, according to Müller et al. [1993], are indicated with blue circles.

A comparison of $1 / Q_{\mu}$ maps for QsADR17 and from three other recent $S$ wave attenuation models, QMU3b [Selby and Woodhouse, 2002], QRFSI12 [Dalton et al., 2008], and QRLW8 [Gung and Romanowicz, 2004], is shown in supporting information Figure S8. QsADR17 displays much stronger contrasts than other models in the depth range $100-250 \mathrm{~km}$. All maps share the ocean-continent difference down to $150 \mathrm{~km}$ depth, with low attenuation beneath most cratons and high attenuation in younger regions. The signature of mid-ocean ridges is clear in QsADR17 and QRFSI12. The correlations between all these $1 / Q_{\mu}$ models computed up to degree 8 are rather low, but the highest correlation is found between QsADR17 and QRFSI12 in the depth range 100-200 km (see supporting information Figure S9b). Their spectral amplitudes are very different, 
and the amplitude variations of QsADR17 are about 3 times larger than in previous models (see supporting information Figure S9d). In spite of these large variations, the quality factor of QsADR17 remains positive. At depths greater than $200 \mathrm{~km}$, spectral amplitudes are low and the agreements between the various models are close to zero.

In Figure 3a, we compute the correlation between QsADR17 and 3D2016_03Sv, our recent $S_{v}$ wave model of the upper mantle [Debayle et al., 2016]. Both models exploit the automated approach of Debayle and Ricard [2012]. While QsADR17 benefits from 372,629 path-average measurements, 3D2016_03Sv is based on a larger data set of 1,391,400 Rayleigh wave measurements. However, up to spherical harmonic $\approx 16$, both models are well constrained by their very large data sets, allowing a safe comparison. Figure 3a shows that at depths greater than $90 \mathrm{~km}$, correlations at all degrees are close or above the $95 \%$ confidence level (i.e., there is $95 \%$ probability that these correlations are not due to chance). However, in the depth range 50-90 km, the correlation is weak or negative for spherical-harmonic degrees <5. Adenis et al. [2017] made a similar observation for the correlation between Rayleigh wave fundamental mode attenuation and phase-velocity maps. Our inversion at depth allows us to locate the origin of the discrepancy, which is maximum in the shallowest part of our model and extends down to $90 \mathrm{~km}$, probably within the lithosphere or at its base in oceanic areas.

In Figures $3 \mathrm{~b}-3 \mathrm{i}$ we compare the $Q_{\mu}$ and $S_{v}$ wave maps at 70 and $150 \mathrm{~km}$ depths. The filtered maps (Figures $3 \mathrm{~d}$ and $3 \mathrm{e}$, and $3 \mathrm{~h}$ and $3 \mathrm{i}$ ) only include degrees 1, 2, and 3, while the raw maps (Figures $3 \mathrm{~b}$ and $3 \mathrm{c}$, and $3 \mathrm{f}$ and $3 \mathrm{~g}$ ) include all spherical harmonic degrees. Differences between the unfiltered maps at $70 \mathrm{~km}$ depth occur beneath continents in Phanerozoic regions (in the region stretching eastward from Europe to Anatolia, Tibet, and the eastern margin of Asia but also in western North America and northeast of Africa) which have a broader signature in velocity than in attenuation. In Figure $3 \mathrm{~d}$ a broad attenuating anomaly encompasses most Pacific hot spots, whereas the strongest low-velocity anomaly is centered beneath the Pacific ridge in Figure 3e. There is also a difference in the sign of the perturbation (high $Q_{\mu}$ and low velocity) under a broad region extending southward from eastern Asia, toward Indonesia, the Philippines and Australia, and westward toward northeast Africa. These differences explain the poor correlations observed for degrees $<5$ in Figure $3 a$. Figures $3 \mathrm{~b}-3 \mathrm{e}$ suggest that at $70 \mathrm{~km}$ depth, $V_{s}$ increases with the age of the seafloor in the Pacific Ocean, while $Q_{\mu}$ displays attenuating anomalies located at various ages, under the East Pacific rise and in the vicinity of most hot spots.

At $150 \mathrm{~km}$ depth the unfiltered $Q_{\mu}$ and $S_{V}$ wave maps share a long wavelength component associated with the difference between continents displaying low attenuation and high velocities and oceans displaying high attenuation and low velocities. This is very clear on the filtered maps (i.e., high $Q_{\mu}$ and $V_{s}$ beneath the Northern Hemisphere continents and low $Q_{\mu}$ and $V_{s}$ beneath the Pacific and Indian Oceans) in agreement with the high correlations observed in Figure $3 a$.

Figure 4 shows age-dependent average cross sections in QsADR17 and 3D2016_03Sv. Global average cross sections are shown in Figure 4 (top row), while in Figure 4 (middle and bottom rows) we split up the Earth surface into plates slower and faster than $4 \mathrm{~cm} \mathrm{yr}^{-1}$. The threshold of $4 \mathrm{~cm} \mathrm{yr}^{-1}$ is chosen after Debayle and Ricard [2013], who observed that only plates moving faster than $4 \mathrm{~cm} \mathrm{yr}^{-1}$ produce sufficient shearing at their base to organize the large-scale flow in the asthenosphere. According to this criterion, fast plates include the Indian, Coco, Nazca, Australian, Philippine Sea, and Pacific plates (Figure 4b).

The $V_{s}$ sections (Figure $4 a$, right column) confirm that $S_{v}$ velocity increases with seafloor age and follow the trend predicted by the square root of age-cooling model [Turcotte and Schubert, 2002]. The main difference in the profiles for fast and slow plates is the fact that the $S_{v}$ velocities in the asthenosphere are lower beneath fast plates, especially for ages older than 80 Myr. The only cratons belonging to a fast-moving plate, the Australian and Indian cratons, appear to be seismically remarkably fast.

The $Q_{\mu}$ sections (Figure 4 a, left column) show more variability than $V_{s}$. For slow plates, the increase of $Q_{\mu}$ with seafloor age is very clear in Figure $4 a$ (middle row), which also shows a deepening of attenuation contours following roughly the square root of age. As for $V_{s}$, a strong reduction in $Q_{\mu}$ is observed in the asthenosphere for ages $\leq 80$ Myr. For fast-moving plates, the attenuation is even stronger in the asthenosphere, but it extends upward through the oceanic lithosphere for seafloor ages between 50 and 140 Myr. This corresponds to the age range in which most Pacific hot spots are found. For ages older than $140 \mathrm{Myr}$ a high $Q_{\mu}$ and high-velocity lithosphere is retrieved. However, in contrast to $V_{s}$, the high $Q_{\mu}$ anomaly extends deeper than the base of 

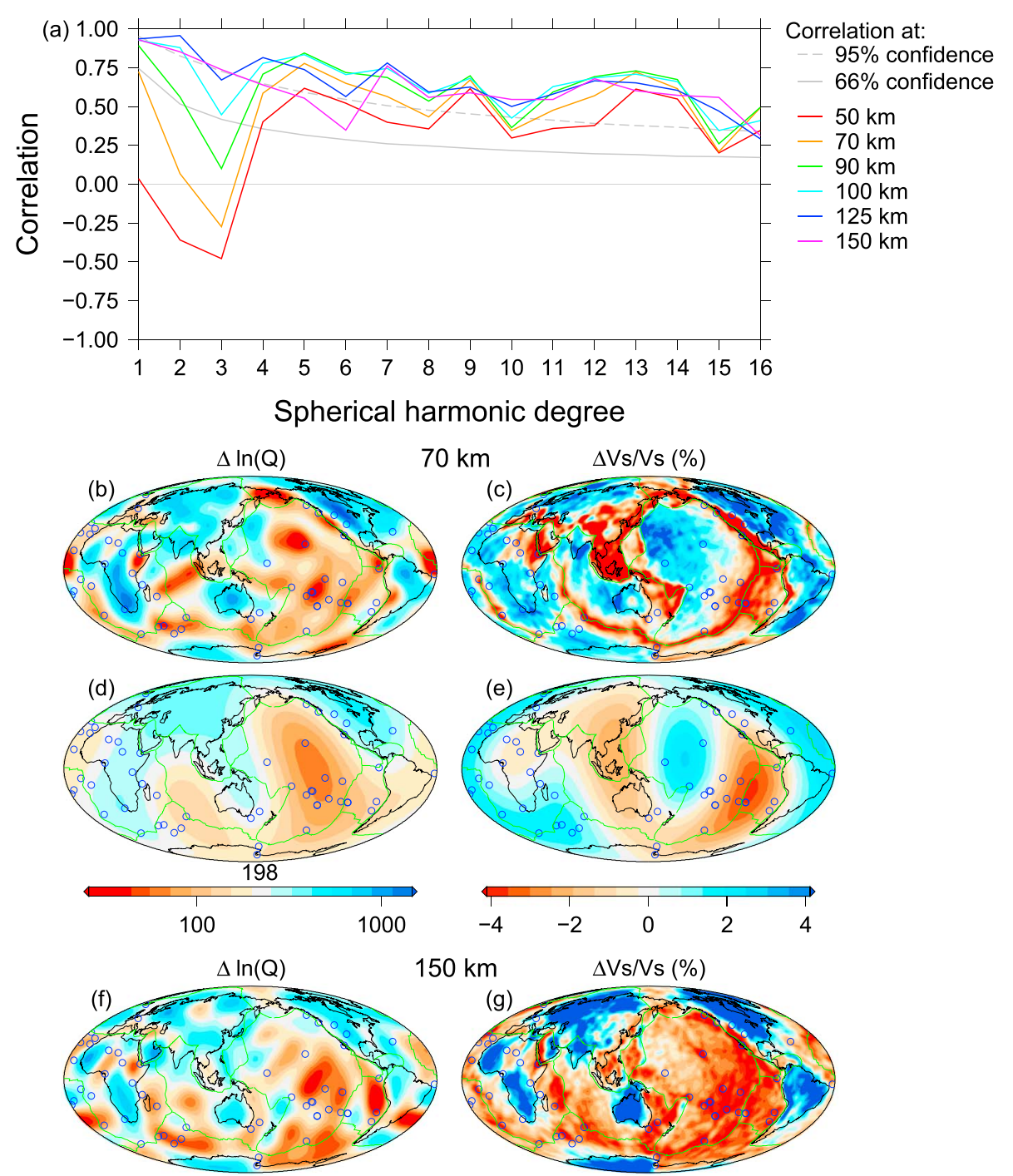

$50 \mathrm{~km} \quad \Delta \mathrm{Vs} / \mathrm{Vs}(\%)$
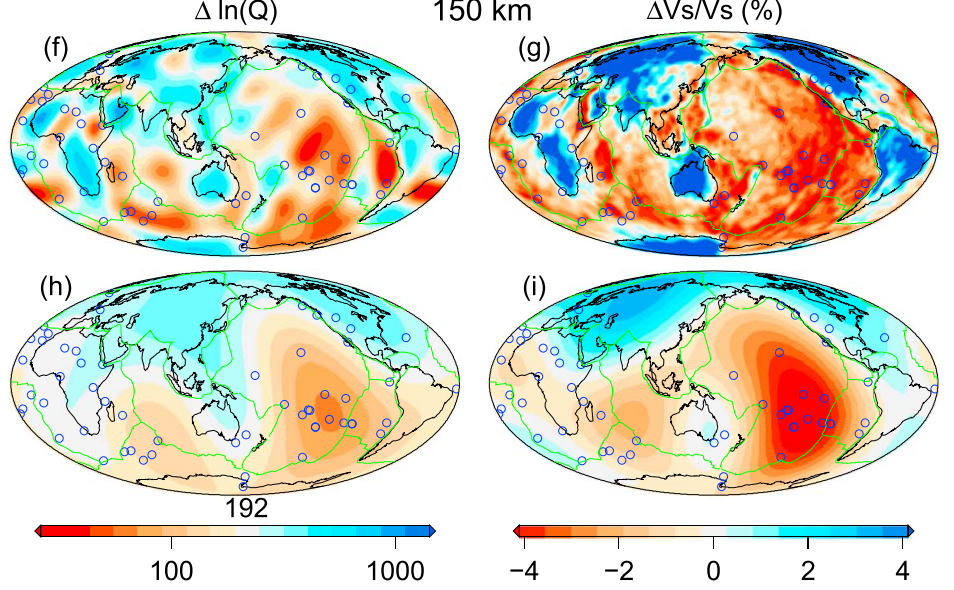

Figure 3. (a) Degree-by-degree correlation coefficient as a function of spherical-harmonic degree between QsADR17 and the shear wave model 3D2016_07Sv by Debayle et al. [2016]. (b-i) Maps of variations in attenuation (left column) and in shear velocity (right column) at 70 and $150 \mathrm{~km}$ depths. We plots raw maps in Figures 3b, 3c, 3f, and $3 \mathrm{~g}$, and we filter out spherical harmonic degrees larger than 4 in Figures 3d, 3e, 3h, and 3i.

the thermal cooling model which might be related to the presence of subduction zones around the Pacific Ocean. In Proterozoic and Archean continents, the low-attenuation lithosphere seems $\sim 50 \mathrm{~km}$ thinner than the seismically fast lithosphere.

\section{Implications}

Temperature has a major effect on both $Q_{\mu}$ and $V_{s}$ and is likely to contribute to their positive correlation at depths greater than $90 \mathrm{~km}$ (Figure 3a). In oceanic regions, the deepening of $V_{s}$ and $Q_{\mu}$ contours with the square root of age suggests that to first order, thermal cooling controls both $Q_{\mu}$ and $V_{s}$, at least beneath slow-moving 


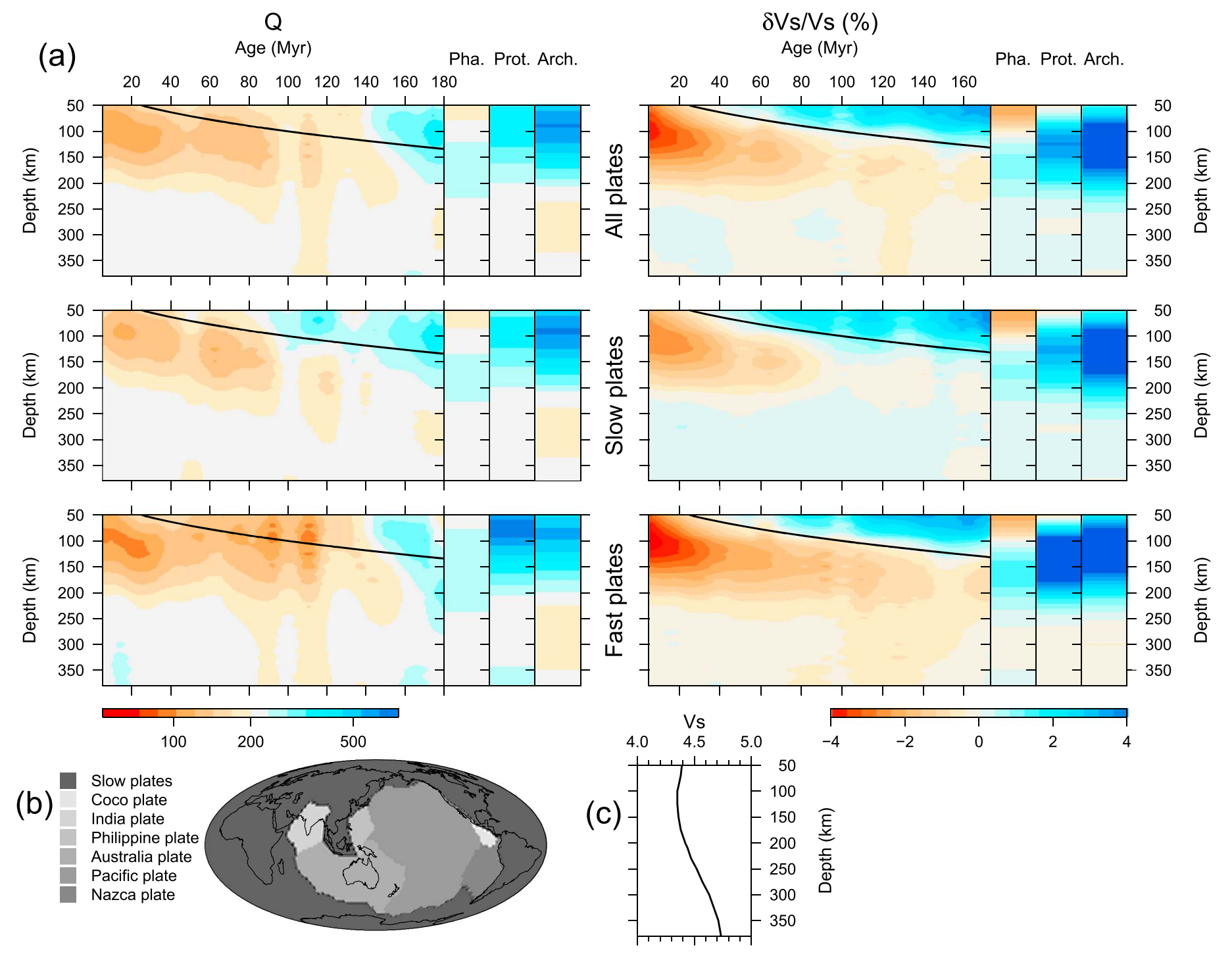

Figure 4. (a) Quality factor (left column) and shear velocity (right column) cross sections with respect to age for oceanic regions and Phanerozoic, Proterozoic, and Archean continental provinces. The quality factor model is QsADR17, while $S$ wave heterogeneities are from model 3D2016_03Sv by Debayle et al. [2016]. For oceanic regions, the displayed parameters are averaged along the Müller et al. [1993] isochrons over a sliding window of 10 Myr. In each section, the continuous black line indicates the thermal boundary layer of the half-space cooling model [e.g., Turcotte and Schubert, 2002], corresponding to the $1100^{\circ} \mathrm{C}$ isotherm. (c) Perturbations in velocity from the reference model are in percent; $Q_{\mu}$ is plotted with a logarithmic scale. (b) The position of the fast and slow plates.

plates. Under fast-moving plates, the low $Q_{\mu}$ observed within the fast $V_{s}$ oceanic lithosphere for seafloor age between 50 and 140 Myr may, in part, be due to thermal plumes, which would have a stronger signature in $Q_{\mu}$ than in $V_{s}$. A number of broad plumes have recently been detected in global $S$ wave tomography beneath some major hot spots in the Pacific Ocean [French and Romanowicz, 2015]. Thermal plumes are expected to produce anomalies at least $1000 \mathrm{~km}$ in diameter, when they spread horizontally in the low-viscosity asthenosphere [Davies and Richards, 1992]. The broad low $Q_{\mu}$ and $V_{s}$ anomaly observed in the Pacific Ocean at depths greater than $90 \mathrm{~km}$ could therefore be produced by several plume anomalies in the asthenosphere. This interpretation could also explain a broad anomaly in radial anisotropy observed in the Pacific Ocean by Ekström and Dziewoński [1998], which is compatible with an enhanced horizontal flow in the asthenosphere favoring the alignment of anisotropic crystals [Maggi et al., 2006]. The stronger temperature dependance of $Q_{\mu}$ may also explain the stronger $Q_{\mu}$ signature of cold subduction zones below the thermal lithosphere for ages older than 140 Myr (Figure 4).

However, it is likely that temperature does not explain the $Q_{\mu}$ and $V_{s}$ variations everywhere. It is, for example, noteworthy that in Figure 4 the signature of cratons extends on average about $50 \mathrm{~km}$ deeper in $V_{s}$ than 
in $Q_{\mu}$ and this difference cannot be attributed to vertical smearing which is identical in both models. Assuming that attenuation is a proxy for temperature, our $Q_{\mu}$ profiles suggest that the thermal lithosphere extends down to about $150 \mathrm{~km}$ beneath cratons, in agreement with previous observations [Dalton et al., 2008]. The existence of deeper $V_{s}$ continental roots could be explained by compositional heterogeneities, possibly due to the extraction of basaltic melt [Jordan, 1975]. Within the oceanic lithosphere, water may also contribute to the increase of attenuation under hot spots, if deep dewatering of wet plumes is incomplete [Karato, 2003]. Finally, we observe a number of regions where low velocities are associated with high $Q_{\mu}$ at depths shallower than $150 \mathrm{~km}$. These regions generally correspond to active tectonic areas (Red Sea and Tibet) or to Phanerozoic provinces where Cenozoic volcanism occurs (East Asia). It has been advocated that melt could have a greater effect on $V_{s}$ than $Q_{\mu}$ on the basis of seismic observations [Yang et al., 2007] and mechanical models [Hammond and Humphreys, 2000a, 2000b]. If correct, partial melt would be a plausible explanation for reconciling low $V_{s}$ with high $Q_{\mu}$ in these regions. In East Asia, melting of wet plumes at the base of lithosphere has been advocated to explain low-velocity zones in the upper mantle [Richard and Iwamori, 2010].

\section{Concluding Remarks}

QsADR17, our new global shear wave attenuation model of the upper mantle, shows a strong correlation with surface tectonics down to $200 \mathrm{~km}$ depth, with low attenuation beneath continents and high attenuation beneath oceans. Attenuating anomalies are found beneath mid-ocean ridges down to $150 \mathrm{~km}$ and under most Pacific hot spots from the lithosphere down to the transition zone. The circumpacific subductions appear as a conspicuous ring of high-quality factor around $250 \mathrm{~km}$ depth.

At depths shallower than $100 \mathrm{~km}$, the broad-scale (i.e., spherical harmonic degrees <5) component of QsADR17 is not correlated with seismic velocities. The Pacific lithosphere displays high velocities between 40 and 140 Myr associated with a strong attenuation which may be due to a strong sensitivity of $Q_{\mu}$ to temperature and possibly water. A number of active regions display low velocities and high $Q_{\mu}$ and may require the presence of partial melting.

In the asthenosphere, QsADR17 is well correlated with S wave models. In the Pacific Ocean, QsADR17 includes a broad-scale component with a strong attenuation at $150 \mathrm{~km}$ depth. This attenuating anomaly is associated with low $V_{S}$ in 3D2016_03Sv and with a broad-scale anomaly in radial anisotropy [Ekström and Dziewoński, 1998]. The existence of several thermal plumes that would pond in the asthenosphere may explain these observations. Finally, the existence of continental roots slightly deeper in $V_{S}$ than $Q_{\mu}$ suggests the presence of compositional heterogeneities at the bases of cratons.

Acknowledgments

This work was supported by the French ANR SEISGLOB ANR-11-BLANC-SIMI5-6-016-01. We thank the IRIS and RESIF data centers for providing broadband data. Our tomographic model QsADR17 will be made freely available to the community via Eric Debayle's webpage (http://perso.ens-lyon.fr/eric.debayle/) on 1 August 2017.

\section{References}

Adenis, A., E. Debayle, and Y. Ricard (2017), Seismic evidence for broad attenuation anomalies in the asthenosphere beneath the Pacific Ocean, Geophys. J. Int., 209(3), 1677-1698, doi:10.1029/2000GL011389.

Billien, M., J. J. Leveque, and J. Trampert (2000), Global maps of Rayleigh wave attenuation for periods between 40 and 150 seconds, Geophys. Res. Lett., 27(22), 3619-3622, doi:10.1029/2000GL011389.

Cara, M., and J. Lévêque (1987), Waveform inversion using secondary observables, Geophys. Res. Lett., 14, 1046-1049.

Dalton, C. A., and G. Ekström (2006), Global models of surface wave attenuation, J. Geophys. Res., 111, B05317, doi:10.1029/2005JB003997.

Dalton, C. A., G. Ekström, and A. M. Dziewoński (2008), The global attenuation structure of the upper mantle, J. Geophys. Res., 113, B09303, doi:10.1029/2007JB005429.

Dalton, C. A., V. Hjorleifsdottir, and G. Ekstrom (2014), A comparison of approaches to the prediction of surface wave amplitude, Geophys. J. Int., 196(1), 386-404, doi:10.1093/gji/ggt365.

Dalton, C. A., X. Bao, and Z. Ma (2017), The thermal structure of cratonic lithosphere from global Rayleigh wave attenuation, Earth Planet. Sci. Lett., 457, 250-262, doi:10.1016/j.epsl.2016.10.014.

Davies, G. F., and M. A. Richards (1992), Mantle convection, J. Geol., 100(2), 151-206, doi:10.1086/629582.

Debayle, E., and Y. Ricard (2012), A global shear velocity model of the upper mantle from fundamental and higher Rayleigh mode measurements, J. Geophys. Res., 117, B10308, doi:10.1029/2012JB009288.

Debayle, E., and Y. Ricard (2013), Seismic observations of large-scale deformation at the bottom of fast-moving plates, Earth Planet. Sci. Lett., 376, 165-177, doi:10.1016/j.epsl.2013.06.025.

Debayle, E., F. Dubuffet, and S. Durand (2016), An automatically updated S-wave model of the upper mantle and the depth extent of azimuthal anisotropy, Geophys. Res. Lett., 43, 674-682, doi:10.1002/2015GL067329.

Durand, S., F. Chambat, J. Matas, and Y. Ricard (2012), Constraining the kinetics of mantle phase changes with seismic data, Geophys. J. Int., 189(3), 1557-1564, doi:10.1111/j.1365-246X.2012.05417.x.

Durek, J. J., and G. Ekström (1996), A radial model of anelasticity consistent with long-period surface-wave attenuation, B. Seismol. Soc. Am., 86(1A), 144-158.

Dziewoński, A., and D. Anderson (1981), Preliminary reference Earth model, Phys. Earth Planet. Inter., 25(4), 297-356, doi:10.1016/0031-9201(81)90046-7.

Ekström, G., and A. M. Dziewoński (1998), The unique anisotropy of the Pacific upper mantle, Nature, 394(6689), 168-172, doi: $10.1038 / 28148$. 
Faul, U., and I. Jackson (2015), Transient creep and strain energy dissipation: An experimental perspective, Annu. Rev. Earth Planet. Sci., 43, 541-569, doi:10.1146/annurev-earth-060313-054732.

French, S., V. Lekic, and B. Romanowicz (2013), Waveform tomography reveals channeled flow at the base of the oceanic asthenosphere, Science, 342(6155), 227-230, doi:10.1126/science.1241514.

French, S. W., and B. Romanowicz (2015), Broad plumes rooted at the base of the Earth's mantle beneath major hotspots, Nature, 525(7567), 95-99, doi:10.1038/nature14876.

Gung, Y., and B. Romanowicz (2004), Geophys. J. Int., 157(2), 813-830, doi:10.1111/j.1365-246X.2004.02265.X.

Hammond, W. C., and E. D. Humphreys (2000a), Upper mantle seismic wave attenuation: Effects of realistic partial melt distribution, J. Geophys. Res., 105(B5), 10,987-10,999, doi:10.1029/2000JB900042.

Hammond, W. C., and E. D. Humphreys (2000b), Upper mantle seismic wave velocity: Effects of realistic partial melt geometries, J. Geophys. Res., 105(B5), 10,975-10,986, doi:10.1029/2000JB900041.

Jackson, I. (2007), 2.17-Properties of rocks and minerals - Physical origins of anelasticity and attenuation in rock A2 — Schubert, Gerald, in Treatise on Geophysics, pp. 493-525, Elsevier, Amsterdam.

Jordan, T. (1975), The continental tectosphere, Rev. Geophys., 13(3), 1-12, doi:10.1029/RG013i003p00001.

Karato, S.-I. (1993), Importance of anelasticity in the interpretation of seismic tomography, Geophys. Res. Lett., 20(15), 1623-1626, doi:10.1029/93GL01767.

Karato, S.-i (2003), Mapping water content in the upper mantle, in Inside the Subduction Factory, Geophys. Monogr. Ser., vol. 138, pp. 135-152, AGU, Washington, D. C.,10.1029/138GM08

Lay, T., and H. Kanamori (1985), Geometric effects of global lateral heterogeneity on long-period surface wave propagation, J. Geophys. Res., 90(B1), 605-621.

Ma, Z., G. Masters, and N. Mancinelli (2016), Two-dimensional global Rayleigh wave attenuation model by accounting for finite-frequency focusing and defocusing effect, Geophys. J. Int., 204(1), 631-649, doi:10.1093/gji/ggv480.

Maggi, A., E. Debayle, K. Priestley, and G. Barruol (2006), Azimuthal anisotropy of the Pacific region, Earth Planet. Sci. Lett., 250(1-2), 53-71, doi:10.1016/j.epsl.2006.07.010.

Müller, R., J. Royer, and L. Lawver (1993), Revised plate motions relative to the hotspots from combined atlantic and Indian Ocean hotspot tracks, Geology, 21, 275-278.

Nataf, H.-C., and Y. Ricard (1995), 3smac: an a priori tomographic model of the upper mantle based on geophysical modeling, Phys. Earth Planet. Inter., 95(1), $101-122$.

Ricard, Y., S. Durand, J. P. Montagner, and F. Chambat (2014), Is there seismic attenuation in the mantle?, Earth Planet. Sci. Lett., 388, 257-264, doi:10.1016/j.epsl.2013.12.008.

Richard, G. C., and H. Iwamori (2010), Stagnant slab, wet plumes and Cenozoic volcanism in East Asia, Phys. Earth Planet. Inter., 183(1-2, SI), 280-287, doi:10.1016/j.pepi.2010.02.009.

Ritsema, J., H. J. van Heijst, and J. H. Woodhouse (2004), Global transition zone tomography, J. Geophys. Res., 109, B02302, doi:10.1029/2003JB002610.

Romanowicz, B. (1990), The upper mantle degree 2: Constraints and inferences from global mantle wave attenuation measurements, J. Geophys. Res., 95(B7), 11,051-11,071, doi:10.1029/JB095iB07p11051.

Romanowicz, B. (1995), A global tomographic model of shear attenuation in the upper mantle, J. Geophys. Res., 100(B7), 12,375-12,394, doi:10.1029/95JB00957.

Romanowicz, B., and B. J. Mitchell (2007), 1.21 - Deep earth structure-Q of the Earth from crust to core, in Treatise on Geophysics, edited by G. Schubert, pp. 731-774, Elsevier, Amsterdam.

Schaeffer, A. J., and S. Lebedev (2013), Global shear speed structure of the upper mantle and transition zone, Geophys. J. Int., 194(1), 417-449, doi:10.1093/gji/ggt095.

Selby, N. D., and J. H. Woodhouse (2002), The Q structure of the upper mantle: Constraints from Rayleigh wave amplitudes, J. Geophys. Res., 107(B5), 2097, doi:10.1029/2001JB000257.

Takeuchi, H., and M. Saito (1972), Seismic surface waves, in Methods in Computational Physics, chap. 11, pp. 217-295, Academic Press, New York.

Tarantola, A., and B. Valette (1982), Generalized nonlinear inverse problems solved using the least squares criterion, Rev. Geophys., 20(2), $219-232$.

Turcotte, D., and G. Schubert (2002), Geodynamics: Second Edition, Cambridge Univ. Press, Cambridge.

Um, J., and F. A. Dahlen (1992), Source phase and amplitude anomalies of long-period surface waves, Geophys. Res. Lett., 19(15), 1575-1578, doi:10.1029/92GL01391.

Warren, L. M., and P. M. Shearer (2002), Mapping lateral variations in upper mantle attenuation by stacking $P$ and $P P$ spectra, J. Geophys. Res., 107(B12), 2342, doi:10.1029/2001JB001195.

Woodhouse, J. H., and Y. K. Wong (1986), Amplitude, phase and path anomalies of mantle waves, Geophys. J. Int., 87(3), 753-773.

Yang, Y., D. W. Forsyth, and D. S. Weeraratne (2007), Seismic attenuation near the East Pacific Rise and the origin of the low-velocity zone, Earth Planet. Sci. Lett., 258(1-2), 260-268, doi:10.1016/j.epsl.2007.03.040. 